University of Nebraska - Lincoln

DigitalCommons@University of Nebraska - Lincoln

3-2009

\title{
The occurrence of illicit and therapeutic pharmaceuticals in wastewater effluent and surface waters in Nebraska
}

\author{
Shannon L. Bartelt-Hunt \\ University of Nebraska-Lincoln, sbartelt2@unl.edu \\ Daniel D. Snow \\ University of Nebraska-Lincoln, dsnow1@unl.edu \\ Teyona Damon \\ University of Nebraska-Lincoln \\ Johnette Shockley \\ University of Nebraska-Lincoln \\ Kyle Hoagland \\ University of Nebraska-Lincoln, khoagland1@unl.edu
}

Follow this and additional works at: https://digitalcommons.unl.edu/watercenterpubs

Part of the Water Resource Management Commons

Bartelt-Hunt, Shannon L.; Snow, Daniel D.; Damon, Teyona; Shockley, Johnette; and Hoagland, Kyle, "The occurrence of illicit and therapeutic pharmaceuticals in wastewater effluent and surface waters in Nebraska" (2009). Faculty Publications from The Water Center. 8.

https://digitalcommons.unl.edu/watercenterpubs/8

This Article is brought to you for free and open access by the Water Center, The at DigitalCommons@University of Nebraska - Lincoln. It has been accepted for inclusion in Faculty Publications from The Water Center by an authorized administrator of DigitalCommons@University of Nebraska - Lincoln. 


\title{
The occurrence of illicit and therapeutic pharmaceuticals in wastewater effluent and surface waters in Nebraska
}

\author{
Shannon L. Bartelt-Hunt, ${ }^{a}$ Daniel D. Snow, ${ }^{\mathrm{b}}$ Teyona Damon, ${ }^{\mathrm{b}}$ \\ Johnette Shockley, ${ }^{\mathrm{a}}$ and Kyle Hoagland ${ }^{\mathrm{c}}$
}

\author{
a Department of Civil Engineering, University of Nebraska-Lincoln, 203B Peter Kiewit Institute, Omaha, NE 68182-0178, USA \\ ${ }^{b}$ Water Sciences Laboratory, University of Nebraska-Lincoln, Lincoln, NE 68583-0844, USA \\ c UNL Water Center, University of Nebraska-Lincoln, Lincoln, NE 68583-0995, USA \\ Corresponding author - S. L. Bartelt-Hunt, tel 402 554-3868, fax 402 554-3288, email sbartelt2@unl.edu
}

\begin{abstract}
Passive samplers were used to develop semi-quantitative estimates of pharmaceutical concentrations in receiving waters influenced by wastewater effluent. The occurrence and estimated concentration of twenty illicit and therapeutic pharmaceuticals and metabolites in surface waters influenced by wastewater treatment plant (WWTP) discharge and in wastewater effluents in Nebraska were determined using Polar Organic Chemical Integrative Samplers (POCIS). Samplers were installed in rivers upstream and downstream of treated WWTP discharge at four sites and in a discharge canal at a fifth location. Based on differences in estimated concentrations determined from pharmaceuticals recovered from POCIS, WWTP effluent was found to be a significant source of pharmaceutical loading to the receiving waters. Effluents from WWTPs with trickling filters or trickling filters in parallel with activated sludge resulted in the highest observed in-stream pharmaceutical concentrations. Azithromycin, caffeine, 1,7-dimethylzanthine, carbamazepine, cotinine, DEET, diphenhydramine, and sulfamethazine were detected at all locations. Methamphetamine, an illicit pharmaceutical, was detected at all but one of the sampling locations, representing only the second report of methamphetamine detected in WWTP effluent and in streams impacted by WWTP effluent.
\end{abstract}

Keywords: pharmaceutical, POCIS, liquid chromatography-mass spectrometry, water, wastewater

\section{Introduction}

Improvements in analytical detection methods for trace organic compounds over the past decade have allowed for the quantification of numerous contaminants, including pharmaceuticals, hormones, and personal-care products in various environmental media. One of the primary sources of these compounds is effluent from wastewater treatment plants (WWTPs) (Glassmeyer et al., 2005; Lee and Rasmussen, 2006; Miao et al., 2004). Although the presence of therapeutic pharmaceuticals in WWTP effluent has been well established, there is limited published information available on the presence of illicit drugs in WWTP effluent. A small number of studies have reported the presence of illicit drugs in WWTP effluents at ng/ L levels, including methamphetamine, MDMA (ecstasy), tetrahydrocannabinol (THC), and cocaine and cocaine metabolites (Bones et al., 2007; Jones-Lepp et al., 2004; Zuccato et al., 2005, 2008). Analysis of illicit drugs in WWTP effluents has been proposed for use as a tool to estimate community-level consumption of illicit drugs and abused pharmaceuticals (Daughton, 2001; Bones et al., 2007; Zuccato et al., 2005). There are also limited studies of the ecotoxicological impacts of chronic low-level exposures of therapeutic or illicit pharmaceuticals in aquatic systems (Fent et al., 2006; Pounds et al., 2008), however, a limited number of ecotoxicological impacts of pharmaceuticals have been reported at environmentally relevant concentrations (Raldua et al., 2008; Schreiber and Szewzyk, 2008). Because these compounds are biologically active, ecotoxicological and human health impacts are of potential concern.

Although the occurrence and concentration of illicit and therapeutic pharmaceuticals are documented using discrete sampling events, there are fewer data available regarding the time-weighted average concentrations of these compounds in receiving waters downstream of WWTP outfalls. Traditional water sampling approaches, such as grab and composite sampling, are shown to be effective for documenting the occurrence of pharmaceuticals, but these sampling techniques only capture information at the time of sample collection, and may miss events such as changes in the flow regime, chemical inputs and/or the influence of precipitation (MacLeod et al., 2007). In addition, continuous on-line sampling methods may be prohibitively expensive. One device that has been developed for use in sampling trace organic compounds is the Polar Organic Chemical Integrative Sampler (POCIS). This sampling device is designed to trap polar organic compounds from water. Its ease of use and apparent resistance to biofouling make it particu- 
larly attractive for determining time-weighted average (TWA) concentrations of organic compounds in water (Alvarez et al., 2004). POCIS have been used previously for both qualitative and quantitative evaluation of pharmaceuticals, pesticides and hormones in surface waters (Alvarez et al., 2004, 2007; Arditsoglou and Voutsa, 2008; Harman et al., 2008; Jones-Lepp et al., 2004; MacLeod et al., 2007; Zhang et al., 2008).

In this study, we evaluated the occurrence and concentration of twenty pharmaceuticals (both illicit and therapeutic) and related metabolites in surface waters upstream and downstream of WWTP outfalls and in WWTP effluent in Nebraska. The treatment plants monitored serve populations ranging from 20,000 to approximately 420,000 and represent a variety of secondary treatment technologies, including trickling filter, activated sludge, trickling filters and activated sludge in parallel, and biological nutrients. The purpose of this study was (1) to evaluate in-stream TWA concentrations of pharmaceuticals in surface waters impacted by WWTP effluents and in WWTP effluent in Nebraska; (2) to determine the impact of secondary treatment type on the occurrence and concentration of pharmaceuticals in receiving waters; (3) to evaluate the use of POCIS as a semi-quantitative tool for assessing organic compound concentrations in surface waters; and (4) to document the presence of an illicit drug, methamphetamine, in WWTP effluents originating from rural municipalities.

\section{Methods and materials}

\subsection{Sampling locations}

Surface waters were sampled upstream and downstream of the WWTP discharge structure at Lincoln, NE; Grand Island, NE; and Columbus, NE. In addition, samplers were installed downstream of the Hastings, NE WWTP. Samples were also obtained from the effluent channel just prior to discharge in the Missouri River at the Omaha, NE WWTP due to the inaccessibility of the receiving water body at this location. See Table 1 for a summary of sampling locations. All samples were obtained between August and October 2006, during fall baseflow when ground water is a primary source of water to the stream sampled.

Additional information related to each WWTP including the community population, the average daily flow, and the secondary treatment technique employed at each facility is given in Table 1.

\subsection{POCIS and sampling methodology}

POCIS, holders and deployment canisters were obtained from Environmental Sampling Technologies (EST, Inc., St. Joseph, MO). Each stainless steel canister was fitted with three pharmaceutical POCIS filled with Oasis HLB sorbent (Waters Corporation, Milford, MA). Each POCIS device had a surface area of $41 \mathrm{~cm}^{2}$ and contained $200 \mathrm{mg}$ of sorbent medium. At each sampling location, canisters were deployed for a 7-day exposure period. At the Grand Island site, the downstream POCIS was recovered 4 weeks after deployment, ostensibly due to vandalism. At sites where upstream and downstream samples were obtained, POCIS devices were deployed at each location simultaneously. All sites were sampled between August and November 2006, when baseflow is a primary source of water in the receiving water bodies. The sampling period was also outside of the required seasonal disinfection period, so no disinfection processes were ongoing at the time of sampling.

\subsection{Solvents and internal standards}

Reference materials, metabolites and labeled standards, including ${ }^{13} \mathrm{C}_{3}$-caffeine and $d_{9}$-methamphetamine, were obtained from Sigma-Aldrich (St. Louis, MO). Phenyl $-{ }^{13} \mathrm{C}_{8}$-sulfamethazine was purchased from Cambridge Isotopes (Andover, MA). Solvents used in sample preparation were high-purity grade (OPTIMA, Fisher Scientific, St. Louis, MO).

\subsection{Extraction methodology}

Handling and elution of POCIS followed procedures described previously (Alvarez et al., 2004; Jones-Lepp et al., 2004). After the 7-day exposure, each individual POCIS device was removed from its deployment canister, briefly rinsed with water if needed to remove debris and opened. The contents of the POCIS were transferred using approximately $20 \mathrm{~mL}$ of high-purity methanol directly into silane-treated vials. Vials containing the methanol and sorbent were held at $-20{ }^{\circ} \mathrm{C}$ until they could be processed for analysis.

Target compounds were eluted by passing $50 \mathrm{~mL}$ of high-purity methanol through silane-treated glass gravity flow chromatography columns into $120 \mathrm{~mL}$ evaporation tubes (RapidVAP, Labconco, Kansas City, MO). Approximately $1 \mathrm{ng}$ of $d_{9}$-methamphetamine, ${ }^{13} \mathrm{C}_{3}$-caffeine, and phenyl- ${ }^{13} \mathrm{C}_{8}$-sulfamethazine internal standards were added to the eluate and used for quantification. Extracts were evaporated under nitrogen to approximately $1 \mathrm{~mL}$, and quantitatively transferred to autosampler vials for analysis by liquid chromatographytandem mass spectrometry (LC/MS/MS). Standards and spiking solutions were prepared from stock solutions $(5 \mu \mathrm{g} / \mu \mathrm{L})$ in methanol. Calibration solutions $(2$, $5,12.5,25$ and $50 \mathrm{pg} / \mu \mathrm{L}$ ) were prepared in 50:50 methanol and water. All standards and extracts were stored in amber vials at $-20^{\circ} \mathrm{C}$.

\subsection{Liquid chromatography-tandem mass spectrometry}

POCIS extracts were analyzed for twenty pharmaceuticals and metabolites, as listed in Table 2. Standards and extracts were analyzed on a Quattro Micro triple quadrupole with a Waters 2695 high pressure liquid chromatograph (HPLC) and autosampler. Electrospray ionization in positive ion mode was used for the detection of target compounds by multiple reaction monitoring (MRM) with argon collision gas. A Thermo (Bellefonte, PA) Betabasic-18 column $(250 \times 2.1 \mathrm{~mm}$, $5 \mu \mathrm{m}, 50^{\circ} \mathrm{C}$ ) was used for separation at a flow rate of $0.2 \mathrm{ml} / \mathrm{min}$ with a gradient of methanol with $0.1 \%$ formic acid in water. Mass spectrometer operational parameters were optimized by infusing each compound separately (Table 2). The source conditions were: capillary $2.5 \mathrm{kV}$, extractor $2 \mathrm{~V}$, RF lens $0.8 \mathrm{~V}$, source temp $90{ }^{\circ} \mathrm{C}$, desolvation temp $400{ }^{\circ} \mathrm{C}$, cone gas flow at $30 \mathrm{~L} / \mathrm{h}$, and desolvation gas flow at $700 \mathrm{~L} / \mathrm{h}$. Compound retention times, ionization modes and MRM transitions are listed in Table 2. A five-point internal standard calibration curve was used for quantification of each analyte. Methamphetamine- $d_{3}$ was used as the internal standard for methamphetamine and d(extro)-amphetamine, phenyl${ }^{13} \mathrm{C}_{8}$-sulfamethazine was used for sulfa antibiotics and ${ }^{13} \mathrm{C}_{3}$-caffeine was used as the internal standard for all other target compounds. Based on the variability of the lowest standard $(2 \mathrm{pg} / \mu \mathrm{L})$, the estimated detection limits for most compounds are less than $1 \mathrm{pg} / \mu \mathrm{L}$, corresponding to $1 \mathrm{ng}$ recovered from the POCIS. Recovery of target compounds was checked by analysis of fortified blanks spiked with known amounts of each compound and averaged $123 \pm 30 \%$. Two laboratory reagent blanks were processed with the POCIS samples, with all compounds below instrument detection limits listed in Table 1.

\subsection{Calculation of POCIS uptake rakes}

In order to use POCIS as a quantitative tool, an uptake rate must be determined for each compound of interest. Compound uptake by POCIS is controlled by the aqueous boundary layer (Alvarez et al., 2004), therefore, the sampling rate, $R_{\mathrm{s}^{\prime}}$ $(\mathrm{L} / \mathrm{d})$ is:

$$
R_{\mathrm{s}}=\left(D_{\mathrm{w}} / L_{\mathrm{w}}\right) * A
$$

where $D_{\mathrm{w}}$ is the aqueous diffusion coefficient of the compound, $L_{\mathrm{w}}$ is the thick ness of the stagnant film layer, and $A$ is the surface area of the sampler. Based on

Table 1. Wastewater treatment facilities sampled in Nebraska

\begin{tabular}{|c|c|c|c|c|c|}
\hline Facility location & $\begin{array}{l}\text { Receiving } \\
\text { water body }\end{array}$ & Sampling locations & $\begin{array}{l}\text { Community population } \\
\text { (year 2006) }\end{array}$ & $\begin{array}{l}\text { Secondary treatment } \\
\text { technique }\end{array}$ & $\begin{array}{l}\text { ge daily } \\
\text { (MGD) }\end{array}$ \\
\hline Columbus, NE & Loup River & $\begin{array}{l}\text { Upstream and downstream } \\
\text { of discharge }\end{array}$ & 20,909 & Activated sludge & 3.4 \\
\hline Grand Island, NE & Wood River & $\begin{array}{l}\text { Upstream and downstream } \\
\text { of discharge }\end{array}$ & 44,546 & Biological nutrients & 12 \\
\hline Omaha, NE & Missouri River & Effluent & 419,545 & Trickling filter & 27.2 \\
\hline
\end{tabular}


Table 2. Pharmaceuticals evaluated and LC-MS parameters

\begin{tabular}{|c|c|c|c|c|c|c|c|c|}
\hline Compound & Use & CAS No. & $\begin{array}{l}\text { Mol. weight } \\
(\mathrm{g} / \mathrm{mol})\end{array}$ & $\begin{array}{l}\text { Retention } \\
\text { time (min) }\end{array}$ & MRM & $\begin{array}{l}\text { Collision } \\
\text { energy }(e V)\end{array}$ & $\begin{array}{l}\text { Cone } \\
\text { voltage }(\mathrm{V})\end{array}$ & $\begin{array}{l}\text { IDL } \\
(\mathrm{ng})\end{array}$ \\
\hline \multicolumn{9}{|l|}{ Non-prescription drugs } \\
\hline Acetaminophen & Analgesic/antipyretic pain reliever & $103-90-2$ & 151.16 & 10.73 & $152>110$ & 14 & 30 & 1.58 \\
\hline Caffeine & Stimulant & $58-08-2$ & 194.19 & 11.94 & $195>138$ & 18 & 32 & 0.33 \\
\hline 1,7-Dimethylxanthine & Caffeine metabolite & $611-59-6$ & 180.16 & 11.25 & $181>124$ & 20 & 32 & 0.61 \\
\hline Cotinine & Nicotine metabolite & $486-56-6$ & 176.22 & 10.30 & $177>78$ & 20 & 35 & 0.28 \\
\hline d-Amphetamine & Stimulant & $51-64-9$ & 135.21 & 10.90 & $136>91$ & 16 & 18 & 0.70 \\
\hline DEET & Insect repellent & $134-62-3$ & 191.27 & 16.70 & $192>119$ & 15 & 25 & 0.66 \\
\hline Diphenhydramine & Antihistamine & $58-73-1$ & 255.35 & 12.89 & $256>167$ & 14 & 25 & 0.35 \\
\hline Methamphetamine & Stimulant & $537-46-2$ & 149.23 & 10.99 & $150>91$ & 20 & 20 & 0.43 \\
\hline \multicolumn{9}{|l|}{ Prescription drugs } \\
\hline Carbamazepine & Anticonvulsive & $298-46-4$ & 236.27 & 15.66 & $237>194$ & 22 & 32 & 0.71 \\
\hline \multicolumn{9}{|c|}{ Veterinary and human antibiotics } \\
\hline Azithromycin & Antibiotic & $83905-01-5$ & 748.98 & 12.63 & $750>592$ & 25 & 40 & 2.79 \\
\hline Sulfachloropyridazine & Antibiotic & $280-32-0$ & 284.72 & 12.20 & $285>156$ & 15 & 24 & 0.60 \\
\hline Sulfamethazine & Antibiotic & $57-68-1$ & 278.33 & 12.03 & $279>156$ & 18 & 30 & 0.43 \\
\hline Sulfadimethoxine & Antibiotic & $122-11-2$ & 310.33 & 13.24 & $311>156$ & 20 & 28 & 0.76 \\
\hline Sulfamethiazole & Antibiotic & $144-82-1$ & 270.33 & 11.68 & $271>156$ & 13 & 24 & 0.17 \\
\hline Sulfamethoxazole & Antibiotic & $723-46-6$ & 253.28 & 12.20 & $254>156$ & 15 & 23 & 0.34 \\
\hline Sulfamerazine & Antibiotic & $127-79-7$ & 264.30 & 11.51 & $265>156$ & 16 & 28 & 0.24 \\
\hline Sulfathiazole & Antibiotic & $72-14-0$ & 255.32 & 10.99 & $256>156$ & 14 & 25 & 0.46 \\
\hline Thiabendazole & Anthelmintic & $148-79-8$ & 201.25 & 12.38 & $202>175$ & 24 & 35 & 0.17 \\
\hline Virginiamycin & Antibiotic & 21411-53-0 & 525.59 & 16.35 & $526>355$ & 16 & 25 & 0.78 \\
\hline \multicolumn{9}{|l|}{ Internal standards } \\
\hline Phenyl- ${ }^{13} \mathrm{C}_{6}$-sulfamethazine & & $57-68-1$ & 284.1 & 11.95 & $285>124$ & 25 & 30 & \\
\hline$d_{9}$-Methamphetamine & & $537-46-2$ & 158.1 & 10.99 & $159>93$ & 18 & 20 & \\
\hline${ }^{13} \mathrm{C}_{3}$-caffeine & & $58-08-2$ & 197.1 & 11.87 & $198>140$ & 18 & 32 & \\
\hline
\end{tabular}

a linear uptake rake, the water concentration of the compound of interest can be calculated as:

$$
C_{\mathrm{w}}=C_{\mathrm{s}} M_{\mathrm{s}} / R_{\mathrm{s}} t
$$

where $C_{w}$ and $C_{\mathrm{s}}$ are the concentrations of the compound in the aqueous and sorbent phases, respectively, $M_{\mathrm{s}}$ is the mass of sorbent, and $t$ is the exposure time.

One limitation of POCIS is the need to determine the uptake rates for the compounds of interest for qualitative analysis. To date, uptake rates have been calculated for a limited number of hormones, pharmaceuticals and personal-care products (Alvarez et al., 2004; Jones-Lepp et al., 2004; MacLeod et al., 2007; Togola and Budzinski, 2007). In this study, we calculated theoretical uptake rates for the pharmaceuticals of interest, and used these values in Equation (2) to determine aqueous concentrations. Based on the uptake rate data collected under turbulent conditions reported by MacLeod et al. (2007) for POCIS containing the Oasis HLB sorbent, and using $D_{w}$ values estimated at $25^{\circ} \mathrm{C}$ using the HaydukLaudie model (Lyman et al., 1982), an average $L_{\mathrm{w}}$ value of $0.025 \pm 0.002 \mathrm{~cm}$ was determined. Based on this value and calculated $D_{\mathrm{w}}$ values, $R_{\mathrm{s}}$ values for the compounds of interest were calculated for the twenty pharmaceutical compounds measured in this study. Table 3 provides the calculated $R_{\mathrm{s}}$ values, as well as a comparison to previously published laboratory values, when available. With the exception of azithromycin, calculated $R_{\mathrm{s}}$ values are within a factor of 2-3 times the $R_{\mathrm{s}}$ values reported from laboratory calibration. It should also be noted that $R_{\mathrm{s}}$ values have been shown to vary significantly with environmental conditions including temperature and salinity (Togola and Budzinski, 2007). Variability within a factor of 2-3 is consistent with variability in contaminant concentrations observed in the field based on continuous monitoring over an extended period (Togola and Budzinski, 2007).

\section{Results and discussion}

Estimated aqueous concentrations of contaminants recovered from POCIS at each sampling location are presented in Table 4. Of the twenty pharmaceutical compounds and metabolites, 17 were detected at no less than one of the sampling sites. dAmphetamine, virginiamycin and sulfathiazole were not detected in any of the POCIS residues. At all sampling locations, there were more occurrences of prescription and non-prescription drugs and human antibiotics than veterinary antibiotics, which were expected based on the municipal source of the discharge. For most of the pharmaceuticals investigated, the recovered mass and estimated concentration of a given compound in the downstream sample was significantly higher than in the sample upstream from the WWTP discharge struc- ture. This result indicates that WWTP effluent is a significant source of pharmaceutical loading to the receiving waters, a finding in agreement with other studies which have also demonstrated WWTP effluent to be a significant source of pharmaceutical loading to the environment (Batt et al., 2006; Kim et al., 2007; Lee and Rasmussen, 2006; Roberts and Thomas, 2006). The pharmaceuticals that were detected in all sampling locations (upstream of discharge structure, downstream of discharge structure, and effluent) were caffeine; 1,7-dimethylxanthine, a caffeine metabolite; cotinine, a nicotine metabolite; DEET, and diphenhydramine. The estimated concentration of these compounds ranged from $1.9 \mathrm{ng} / \mathrm{L}$ to $30.3 \mathrm{ng} / \mathrm{L}$ in the

Table 3. Calculated $R_{\mathrm{s}}$ values and comparisons to literature data

\begin{tabular}{|c|c|c|c|}
\hline Compound & $\begin{array}{l}\text { Calculated } \\
\text { flowing } \\
R_{\mathrm{s}}(\mathrm{L} / \mathrm{d})\end{array}$ & $\begin{array}{l}\text { Experimental } \\
\text { flowing } \\
R_{\mathrm{s}}(\mathrm{L} / \mathrm{d})^{\mathrm{a}}\end{array}$ & Source \\
\hline Acetaminophen & 0.30 & & \\
\hline Caffeine & 0.27 & 0.1 & $\begin{array}{l}\text { Togola and } \\
\text { Budzinski (2007) }\end{array}$ \\
\hline 1,7-Dimethylxanthine & 0.33 & & \\
\hline Cotinine & 0.24 & & \\
\hline d-Amphetamine & 0.26 & & \\
\hline DEET & 0.19 & & \\
\hline Diphenhydramine & 0.15 & & \\
\hline Methamphetamine & 0.22 & 0.089 & Alvarez et al. (2007) \\
\hline Carbamazepine & 0.20 & $0.31,0.3$ & $\begin{array}{l}\text { MacLeod et al. (2007) } \\
\text { and Togola and } \\
\text { Budzinski (2007) }\end{array}$ \\
\hline Azithromycin & 0.06 & 0.27 & Alvarez et al. (2007) \\
\hline Sulfachloropyridazine & 0.20 & & \\
\hline Sulfamethazine & 0.18 & 0.10 & MacLeod et al. (2007) \\
\hline Sulfadimethoxine & 0.17 & & \\
\hline Sulfamethiazole & 0.21 & & \\
\hline Sulfamethoxazole & 0.21 & & \\
\hline Sulfamerazine & 0.20 & & \\
\hline Sulfathiazole & 0.22 & & \\
\hline Thiabendazole & 0.27 & & \\
\hline Virginiamycin & 0.09 & & \\
\hline
\end{tabular}

a Values represent experimental data reported for $41 \mathrm{~cm}^{2}$ POCIS under flowing (turbulent) conditions. 


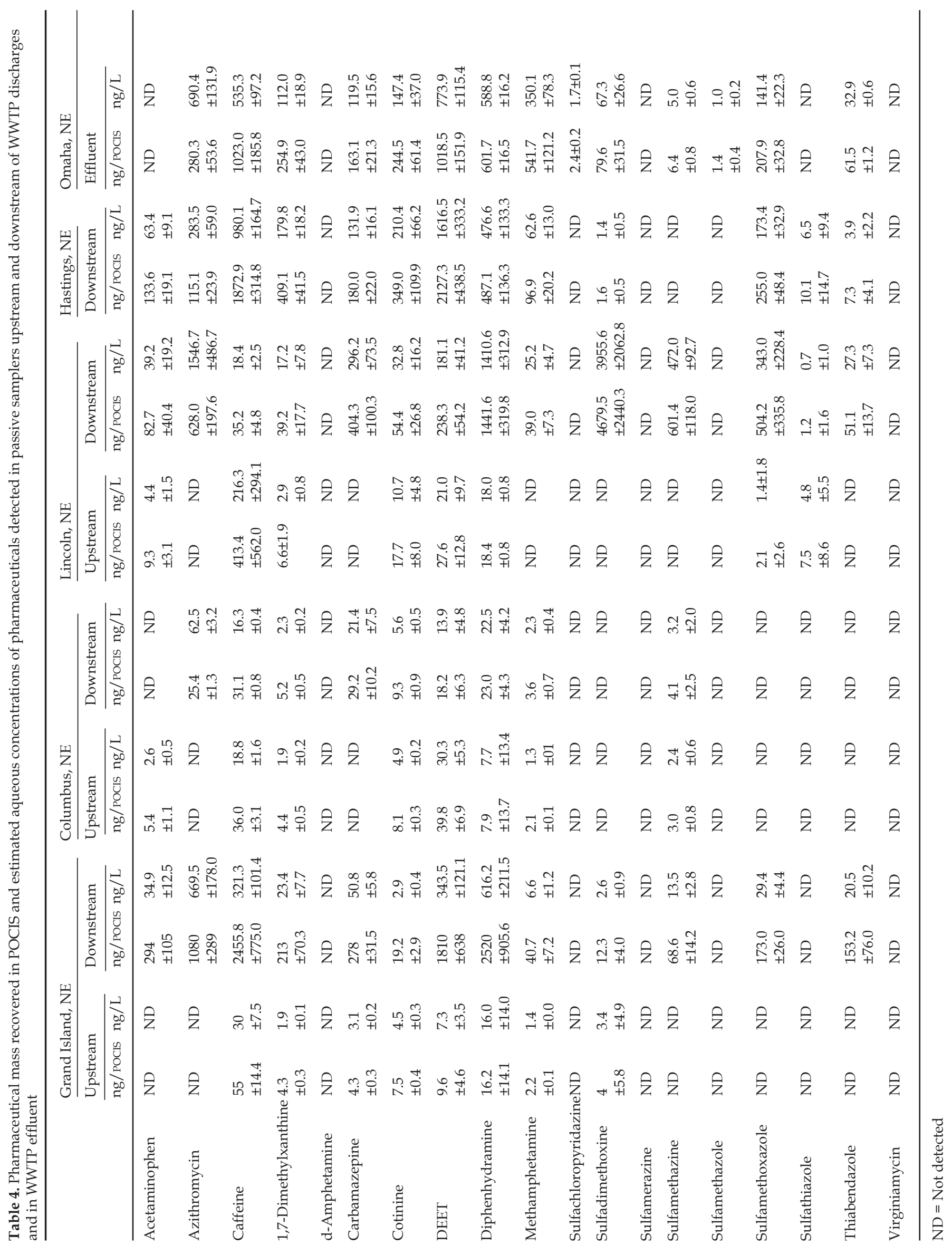


upstream samples and $2.3 \mathrm{ng} / \mathrm{L}$ to approximately $1600 \mathrm{ng} / \mathrm{L}$ in the downstream samples. It should be noted that caffeine was detected upstream of the Lincoln, NE WWTP at a concentration of $216 \mathrm{ng} / \mathrm{L}$, which is significantly higher than the downstream concentration observed at this site. The presence of these compounds in the upstream samples indicates that they may be persistent in the environment or that surface run-off is a significant source of these contaminants. Acetaminophen, azithromycin and carbamazepine were also detected at a large number of the sampling locations. Acetaminophen was detected at all sampling locations with the exception of the upstream sample at Grand Island, NE; the downstream sample at Columbus, NE; and the effluent sample at Omaha, NE. Azithromycin was not detected in any of the upstream samples, but was detected in all downstream and effluent samples and carbamazepine was detected in all sampling locations with the exception of the upstream samples at Columbus, NE and Lincoln, NE. The presence of azithromycin and carbamazepine in all of the effluent and downstream samples, but not in the upstream samples, suggests that surface run-off is not a significant source of these compounds or that they may be more readily degraded in surface waters or preferentially sorbed to sediments.

The WWTPs sampled represent a variety of secondary treatment types, including activated sludge, trickling filter, trickling filter and activated sludge in parallel, and biological nutrients. Although concentrations of pharmaceuticals in the raw sewage at each location were not monitored, it is expected that they would be similar as municipal sources are the primary source of wastewater to each of these WWTPs. Therefore, evaluation of the in-stream pharmaceutical concentrations downstream of the discharge structure at each WWTP should provide some qualitative information about the relative performance of each treatment technology for removal of pharmaceuticals in wastewater. As seen in Figure 1, for the 13 compounds measured in common at each of the four WWTPs where in-stream measurements were taken, the activated sludge treatment results in the lowest pharmaceutical concentration for all compounds with the exception of cotinine. Pharmaceutical concentrations in the streams impacted by effluents from WWTPs with trickling filters or trickling filters in parallel with activated sludge resulted in the highest observed in-stream pharmaceutical concentrations. This result is in agreement with previous studies that have determined that trickling filter secondary treatment systems yield larger organic wastewater contaminant concentrations when compared with activated sludge processes (Carbella et al., 2004; Lee and Rasmussen, 2006).
Trace levels of the illicit drug methamphetamine were detected at most sampling locations. The other illicit pharmaceutical and methamphetamine metabolite, d-amphetamine, was not detected in any of the POCIS. These data represent only the second report of methamphetamine detected in WWTP effluent and in streams impacted by WWTP effluent. Previously, Jones-Lepp et al. (2004) reported estimated methamphetamine concentrations of $1.3 \mathrm{ng} / \mathrm{L}$ and $0.8 \mathrm{ng} / \mathrm{L}$ from POCIS in WWTP effluent and in-stream samples, respectively. These samples were obtained at a WWTP located in Las Vegas, Nevada, a large metropolitan area. In this study, estimated methamphetamine concentrations in about half of the samples were comparable to those reported from Las Vegas, while estimated levels in the WWTP effluent and downstream samples from three sites were $350 \mathrm{ng} / \mathrm{L}$ (effluent) and 2.3-62.6 ng/L (downstream). The effluent sample was obtained from Omaha, NE, which has a population of 491,000 , while the downstream samples were obtained from municipalities with populations ranging from 20,000 to 240,000 . The differences between data obtained from these locations and previously reported results may reflect differences in drug use, wastewater treatment practices and timing of sample collection. The prevalence of trace levels of methamphetamine, caffeine, 1,7-dimethylzanthine, and several other pharmaceuticals may also suggest the presence of positive interferences for these compounds. Although LC-tandem mass spectrometry is among the most sensitive and selective methods available for the detection of polar organic compounds, it is not immune from false positives (Pozo et al., 2006). The use of isotope-labeled analogues as internal standards for selected target analytes (caffeine, methamphetamine, and sulfamethanzine) increases the selectivity of the analysis for these compounds.

The use of passive samplers which can develop information on time-weighted average concentrations of contaminants in water samples can be used effectively for semi-quantitative analysis of polar compounds such as pesticides, pharmaceuticals, and hormones. As stated previously, the limitation of POCISs is the need to perform laboratory calibration experiments to determine contaminant uptake rates. As demonstrated by Togola and Budinski (2007), the magnitude of the uptake rate can be influenced by the environmental conditions of the water matrix, including salinity and temperature. Based on the results from this study, the theoretical uptake rates calculated based on the calculated stagnant film layer and water diffusion coefficient are reasonable when compared to uptake rates calculated from laboratory calibration experiments. The use

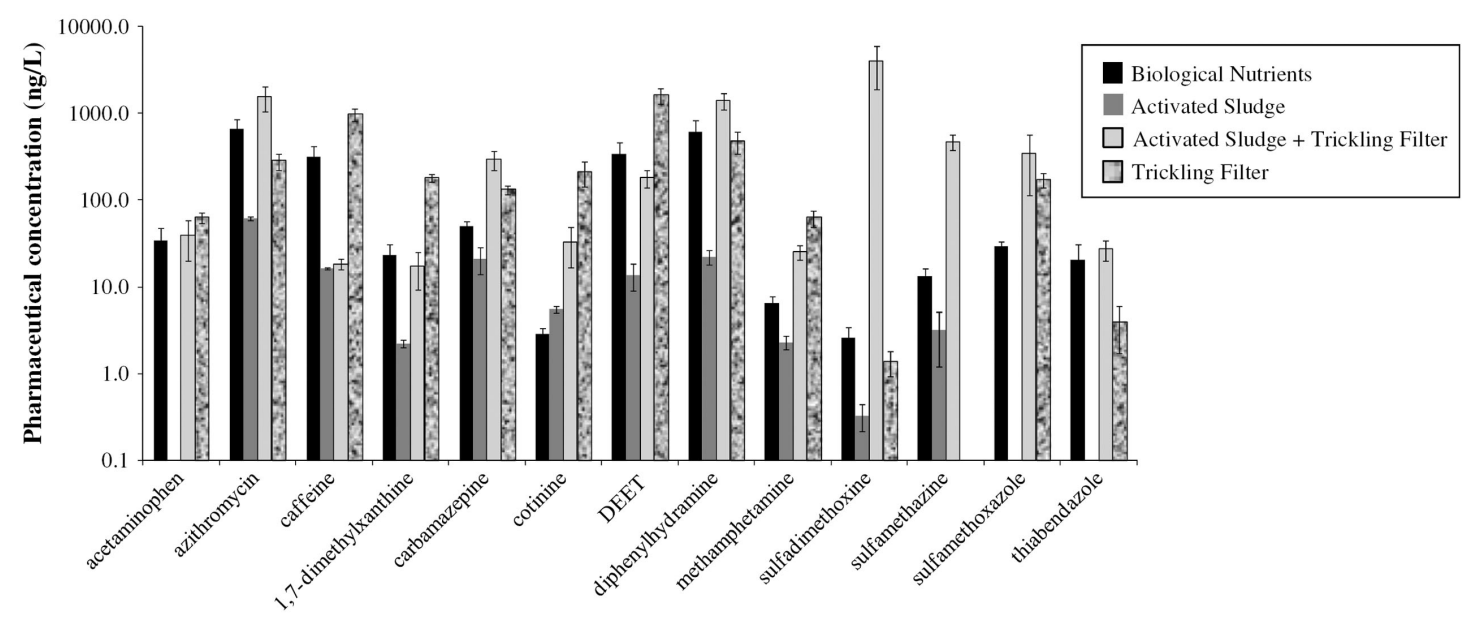

Figure 1. Estimated in-stream pharmaceutical concentrations downstream from WWTP discharge structure as a function of secondary treatment type. 
of calculated uptake rates to predict aqueous concentrations makes the POCIS more attractive for use in experimental studies when quantitative or semi-quantitative data are required and uptake rates determined from laboratory calibration are not available. Further research is needed to fully characterize how different environmental variables influence contaminant uptake rates for POCIS to fully assess whether calculated uptake rates can be used to quantify POCIS results.

\section{Conclusions}

POCIS were deployed in receiving waters upstream and downstream of wastewater treatment plant discharge structures and in one wastewater effluent channel. Calculated uptake rates were reasonable when compared with previously published uptake rates determined by laboratory experiments, and were used to determine estimated aqueous concentrations of nineteen pharmaceutical compounds and metabolites. Concentrations upstream and downstream of the WWTP discharge structure indicate that wastewater is a significant contributor to pharmaceutical loadings in receiving waters. Trace concentrations of methamphetamine, an illicit pharmaceutical, were present in all but one sampling location at higher concentrations than have been previously reported for this compound.

\section{References}

Alvarez et al., 2007 D. A. Alvarez, J. N. Huckins, J. D. Petty, T. Jones-Lepp, F. Stuer-Laridsen, D. T. Getting, J. P. Goddard and A. Gravell, Tool for monitoring hydrophilic contaminants in water: polar organic chemical integrative sampler (POCIS). In: R. Greenwood, G. Mills, and B. Vrana, Editors, Comprehensive Analytical Chemistry vol. 48, Elsevier (2007), pp. 171-197.

Alvarez et al., $2004 \rightarrow$ D. A. Alvarez, J. D. Petty, J. N. Huckins, T. L. Jones-Lepp, D. T. Getting, J. P. Goddard, and S. E. Manaham, Development of a passive, in situ, integrative sampler for hydrophilic organic contaminants in aquatic environments, Environmental Toxicology and Chemistry 23 (2004), pp. 1640-1648.

Arditsoglou and Voutsa, 2008 A. Arditsoglou and D. Voutsa, Passive sampling of selected endocrine disrupting compounds using polar organic chemical integrative samplers, Environmental Pollution 156 (2008), pp. 316-324.

Batt et al., 2006 A. L. Batt, I. B. Bruce, and D. S. Aga, Evaluating the vulnerability of surface waters to antibiotic contamination from varying wastewater treatment plant discharges, Environmental Pollution 142 (2006), pp. 295-302.

Bones et al., 2007 J. Bones, K. V. Thomas, and B. Paull, Using environmental analytical data to estimate levels of community consumption of illicit drugs and abused pharmaceuticals, Journal of Environmental Monitoring 9 (2007), pp. 701-707.

Carbella et al., 2004 M. Carbella, F. Omil, J. M. Lema, M. Llompart, C. Garcia-Jares, I. Rodriquez, M. Gomez, and T. Ternes, Behavior of pharmaceuticals, cosmetics and hormones in a conventional wastewater treatment plant, Water Research 38 (2004), pp. 2918-2926.

Daughton, 2001 C. G. Daughton, Illicit drugs in municipal sewage. In: C. Daughton, and T. Jones-Lepp, Editors, Pharmaceutical and Personal Care Products in the Environment - Scientific and Regulatory Issues, American Chemical Society Symposium Series vol. 791 (2001), pp. 348-364 Washington, D. C. .

Fent et al., 2006 K. Fent, A. A. Weston, and D. Caminada, Ecotoxicology of human pharmaceuticals, Aquatic Toxicology 76 (2006), pp. 122-159.

Glassmeyer et al., 2005 S. Glassmeyer, E. T. Furlong, D. W. Kolpin, J. D. Cahill, S. D. Zaugg, S. L. Werner, M. T. Meyer, and D. D. Kryak, Transport of chemical and microbial contaminants from known wastewater discharges: potential for use as indicators of human fecal contamination, Environmental Science and Technology 39 (2005), pp. 5157-5169.

Harman et al., 2008 C. Harman, O. Boyum, K. N. Tollefsen, K. Thomas, and M. Grung, Uptake of some selected aquatic pollutants in semipermeable membrane devices (SPMDs) and the polar organic chemical integrative sampler (POCIS), Journal of Environmental Monitoring 10 (2008), pp. 239-247.

Jones-Lepp et al., 2004 T. L. Jones-Lepp, D. A. Alvarez, J. D. Petty, and J. N. Huckins, Polar organic chemical integrative sampling and liquid chromatography-electrospray/ion-trap mass spectrometry for assessing selected prescription and illicit drugs in treated sewage effluents, Archives of Environmental Contamination and Toxicology 47 (2004), pp. 427-439.

Kim et al., 2007 S. D. Kim, J. Cho, I. S. Kim, B. J. Vanderford, and S. A. Snyder, Occurrence and removal of pharmaceuticals and endocrine disruptors in South Korean surface, drinking, and waste waters, Water Research 41 (2007), pp. 1013-1021.

Lee and Rasmussen, $2006>$ C. J. Lee and T. J. Rasmussen, Occurrence of organic wastewater compounds in effluent-dominated streams in Northeastern Kansas, Science of the Total Environment 371 (2006), pp. 258-269.

Lyman et al., 1982 In: W. Lyman, W. Reehl, and D. Rosenblatt, Editors, Handbook of Chemical Property Estimation Methods: Environmental Behavior of Organic Compounds, McGraw-Hill, New York, NY (1982).

MacLeod et al., 2007 S. L. MacLeod, E. L. McClure, and C. S. Wong, Laboratory calibration and field deployment of the polar organic chemical integrative sampler for pharmaceuticals and personal care products in wastewater and surface water, Environmental Toxicology and Chemistry 26 (2007), pp. 2517-2529.

Miao et al., 2004 X. Miao, F. Bishay, M. Chen, and C. D. Metcalfe, Occurrence of antimicrobials in the final effluents of wastewater treatment plants in Canada, Environmental Science and Technology 38 (2004), pp. 3533-3541.

Pounds et al., 2008 N. Pounds, S. Maclean, M. Webley, D. Pascoe, and T. Hutchinson, Acute and chronic effects of ibuprofen in the mollusc Planorbis carinatus (Gastropoda: Planorbidae), Ecotoxicology and Environmental Safety 70 (2008), pp. 47-52.

Pozo et al., 2006 O. J. Pozo, J. V. Sancho, M. Ibanez, F. Hernandex, and W. M. A. Niessen, Confirmation of organic micropollutants detected in environmental samples by liquid chromatography tandem mass spectrometry: achievements and pitfalls, Trends in Analytical Chemistry 25 (2006), pp. 1030-1042.

Raldua et al., 2008 D. Raldua, M. Andre, and P. Babin, Clofibrate and gemfibrozil induce an embryonic malabsorption syndrome in zebrafish, Toxicology and Applied Pharmacology 228 (2008), pp. 301-314.

Roberts and Thomas, 2006 P. H. Roberts and K. V. Thomas, The occurrence of selected pharmaceuticals in wastewater effluent and surface waters of the lower Tyne catchment, Science of the Total Environment 356 (2006), pp. 143-153.

Schreiber and Szewzyk, 2008 F. Schreiber and U. Szewzyk, Environmentally relevant concentrations of pharmaceuticals influence the initial adhesion of bacteria, Aquatic Toxicology 87 (2008), pp. 227-233.

Togola and Budzinski, 2007 A. Togola and H. Budzinski, Development of polar organic integrative samplers for analysis of pharmaceuticals in aquatic systems, Analytical Chemistry 79 (2007), pp. 6734-6741.

Zhang et al., $2008-$ Z. Zhang, A. Hibberd, and J. L. Zhao, Analysis of emerging contaminants in sewage effluent and river water: comparison between spot and passive sampling, Analytica Chimica Acta 607 (2008), pp. 37-44.

Zuccato et al., 2008 E. Zuccato, S. Castiglioni, R. Bagnati, C. Chiabrando, P. Grassi, and R. Fanelli, Illicit drugs, a novel group of environmental contaminants, Water Research 42 (2008), pp. 961-968.

Zuccato et al., $2005>$ E. Zuccato, C. Chiabrando, S. Castiglioni, D. Calamari, R. Bagnati, S. Schiarea, and R. Fanelli, Cocaine in surface waters: a new evidence-based tool to monitor community drug use, Environmental Health 4 (2005), pp. 14-21. 